\title{
Innovation of Ideological and Political Education in the Big Data Age
}

\author{
Huiming Li \\ Harbin University of Commerce, Harbin Heilongjiang, 150028, China \\ swx03390lhm@126.com
}

Keywords: Big data age; College and University; Ideological and political education; Network mechanism

\begin{abstract}
The big data age has played a very important role in the environment, subject or object of the current college ideological and political education, and it has also change significantly. In this context, if traditional ideological and political education methods and concepts are still adopted the feudal technical means are still use, it will be difficult to unify the development of the times. So in the future education we should keep up with the development of the times closely enough, grasp the opportunities, meet the challenge of times development. In view of this situation, this article will further explore and construct the network mechanism of the ideological and political education, which is an important way and mean to realize development and grasp opportunities. With the rapid development of information technology in China, especially the gradual rise of mobile Internet and social platform, it means that human society is beginning to move towards big data times. Then what are the core ideas of the big data? That is: the whole new development and changing of society. It can be said that the coming of big data age is not only the reform of life and work style, but also the reform of thinking. Therefore, it is necessary to carry out ideological and political education in colleges and universities [1]. Under the background of the new ideological and political. Our country's education work in colleges and universities is facing new challenges and change, Ideological and political education workers should be fully aware of the big changes that the big data brought .To further strengthen the awareness of innovation, improving the ability of applicating the data giving play to the technical advantages of big data technology. To improve precision of university's ideological and political education work constantly, grasp the deep law of ideological and political education work. But after the author's research, determining the current network mechanisms of ideological and political education of our country, the era of the big data are lack of in-depth research, so the way of working is also lacking certain rationality. For this kind of situation, this article will focus on the construction of network mechanism, to further explore a basic path of ideological and political education in the big data age and the development direction, in order to provide good help for the work.
\end{abstract}

\section{The change of education in university ideology and politics under the background of big data}

About the definition of big data, relatively representative concept is $3 \mathrm{v}$ and $4 \mathrm{v}$ definition, $3 \mathrm{v}$ means the big data have variety, volume and velocity, and $4 \mathrm{v}$ is based on the above, add a value. It can be said that the current college ideological and political education still exists in the change, mainly in the following aspects:

\subsection{The changes in the education environment of university ideology and politics.}

The emergence of the era of big data characteristic of $4 \mathrm{v}$ can say on fundamental link changed the traditional ideological and political education environment, which contains not only the social environment, also contains any cultural environment and technology environment. In the social environment, big data is very good to realize the seamless connection of social information, under the background of this information can be spread in a variety of media, and can be achieved in the process of time or space limit. Big data at the same time can also be the spread of ideas of 
information, students under the background of this time can be involved in the social public opinion, but due to the complex and diverse information, so it is easy to appear the thought, change or values change [2]. In the cultural environment, big data era of the social culture of change and improvement, also will largely affect the culture way of produce, further to the development of the carrier of culture and forms to diversify.

\subsection{The change of the subject and object in education.}

In the process of changing the education environment of ideological and politics in colleges and universities, in the age of big data, the ideological and political education of colleges and universities also has important changes in subject and object. The first link is the students. College students, as an important part of colleges education, are the main body of teachers' teaching work. Therefore, in the process of making changes to college students, it should be focused on individual behaviors, and it should also be reflected in the life, study and way of students. In this process, the most important thing is to change the way of education for students, let students really become the subject of the course education so that students in the process of practical learning and development could not be eliminated by age and society.

\section{The challenges and opportunities of education in our country which is under the era of big data}

\subsection{The challenge of the education work of ideological and political institutions in colleges and universities.}

The data acquisition volume is huge, which has huge information value and also causes problems of storage data. Wide variety and huge memory are the basic characteristics of the big data. For ideological and political education, it's true that big data have great information value. To collect and analyze after obtaining first-hand data, we can learn about the various aspects or behavioral preferences of students in colleges and universities which enables the university ideological and political education work to a target. In this way, it is necessary for universities to set up specialized big data analysis departments. On the basis of continuous development of platform construction, the data of students' daily behaviors were analyzed by professional data analysts. Making full use of the concrete practice of value that the big data presents. It not only could grasp the development characteristics of current college students, but also make specific work more targeted and precision. But for universities, the local area network (LAN) based on information network center. In the daily use of the network electronic platform, universities and various departments in the electronic platform daily work, as well as the interaction of the campus security service network and so on. These areas will produce a lot of instantaneous data in the daily life, however the data collected is huge and trend to increase. If there are no dedicated personnel to manage the data in the colleges and universities then most of the information could only be buried or lost with the accumulation of data. So the data leakage and other information will also occur when the data is processed.

\subsection{Opportunities for university ideological and political education work.}

The potential data value has both broad development prospect and need a large amount of talent investment. Big data has become the important tool that people use to observe human behavior and to predict the development of the market. The main way is through making a reference to the individual or organization's decision and analyzing the current situation and trend of the data. Therefore, the larger the data, the stronger the ability to reflect the reality of the facts, the more complete the information contained, and more reliable it be as an objective decision reference. At the same time from the perspective of data analysis, the complex of the big data collection can be more perfectly embody the basic characteristics of the students, and could also be more accurately to reflect the comprehensive strength of a school. These are all with big data collection of all aspects of the object shown to reflect, so the application of the big data is not only can help the ideological and political education workers to understand students. It be used as an important theory 
basis to the development of school leadership analysis.

\section{The main content of constructing university mechanism of network ideology and politics}

Mechanism of network ideological and political education majorly make students as individual units, which is based on the collection information about students' thought and behavior, making a detailed forecast of the students' thought methods, thus helping students build a more correct and scientific thought, the behavioral specification.

\subsection{Resource allocation mechanism.}

In order to realize the students' ideological and political education, teachers should be equipped with certain manpower, material resources or financial resources in the actual teaching process [3]. The first thing to do is to raise the awareness of big data and improve the accuracy of the work of education. As for how to strengthen the consciousness of the large data of the ideological and political education work in colleges and universities, the colleges and universities shall unified requirements, cooperate with relevant departments to collect, collate and summarize the relevant data in the school and continuously to improve their analysis level. Secondly, we should improve the big data technology and explore the regularity of education work. Coming of the age of big a, in the context of the talent team construction in our country's colleges and universities, There are mostly divided into administrative work and teaching post two kinds, it is difficult to make a structural adjustment in a short period of time, to adapt to the big data analysis and teaching post two kinds, it is difficult to make a structural adjustment in a short period of time , to adapt to the big data analysis and the actual demand of ideological and political education work. Network education requires teachers to educate individually for one person or one group. Therefore, it also requires teachers to be extensive and comprehensive in the human education and application of data.

\subsection{Feedback communication mechanism.}

The situation of college ideological and political education should be conducted effectively under the feedback communication mechanism. Information feedback plays a particularly important role in the work of ideological and political education in colleges and universities. This is because it could grasp the student's thought dynamics timely and provide the basis for the decision-making of education department of the ideology and politics.

But after the author's practical research, determining the traditional communication feedback mechanism in the process of the information feedback still lack some of the abilities. The main reason for this that is the different colleges or classes have their own affairs in the process of education and work, so that the information cannot be effectively feedback and communication. Therefore, this requires the school to fully demonstrate the importance of grid reclassification function and information account in education. Under the system of scientific norms, efforts should be made to create a well atmosphere of information feedback, so as to be an important guarantee to make the ideological and political education information feedback play. In this way, students can not only communicate directly with students, but also the information will be acquired timely to make the information more accurate and timely processing [4]

\subsection{Emergency response mechanism.}

The probability of college students' emergencies is relatively small, but the comprehensive effect that emergency treatment of ideological and political work is strong, therefore it is necessary to have a deep talk constantly. This mechanism a kind of settlement mechanism which is mainly aimed at the emergent behavior of student, the networked way of working can realize that students would master information timely, but does not mean that shall be able to solve the problem timely. So there is a need for an emergency response mechanism in the process, in order to guide or correct students' thoughts or behavior problems efficiently to provide a good help to the development of the students [5].

Meanwhile, in order to reduce the chance and consequence of emergencies, it is necessary to 
improve the emergency handling ability of ideological and political work in college students' emergencies, which depends on the guidance of students to education. It's important to comprehensively implement the quality education, to strengthen and improve the teaching of "two courses" and the situation policy lesson, firmly occupy the ideological and political education main position is the fundamental way.

\section{Conclusions}

In conclusion, under the background of the age of big data. The process of the ideological and political education in colleges and universities appeared very obvious change, this is not only an opportunity but also a serious challenge for the development of colleges and universities, because it requires the reform of colleges and universities should make corresponding to adapt the demand of modern society. The age of big data has played a very important role in the environment, subject or object of the current college ideological and political education. At the same time, it has also undergone significant changes. In this context, if still use the traditional way of ideological and political education and ideas, adopt feudal technology, then it will be difficult to reconcile with the development of the times. Therefore, it is hoped that the study of this paper will help the educators to a certain extent, to realize the good development of colleges and universities.

\section{Acknowledgements}

This work was financially supported by the Innovation of Ideological and Political Education in the Big Data Age (16KSD01).

\section{References}

[1] Mi Hua-quan, Song Xiao, The Gird Mechanism of College Ideological Political Education in the Age of Big Data [J]. Journal of Henan Polytechnic University (Social Sciences), Vol.15, No4, Dec. 2014:487-491

[2] Wang Hongming, Chen Ruisan. On the Problems and Countermeasures of College Students' Ideological and Political Education in the Background of Big Data, Journal of Shenyang Jianchu University (Social Science Edition) 2016, 18(1):76-79

[3] Lin Zhida. The Path of Improving the Timeliness of Ideological and Political Education of College Students in the Era of Big Data, Journal of Hubei University of Economics (Humanities and Social Sciences), 2016, 13(8):156-157

[4] Liu Fengming, Ai Tiantian, On the Innovation of College Students' Ideological and Political Education in the Context of "Micro-era", Journal of Xinyang Normal University(Philosophy and Social Sciences),2016,36(5):15-17

[5] Sun Kaipeng. A Study on the Path of College Students' Ideological and Political Education in the Context of Network and Big Data, Education and Teaching Forum,2016,8(52):184-186. 